\title{
Sampling location, herd size, and season influence Mycobacterium avium ssp. paratuberculosis environmental culture results
}

\author{
R. Wolf, ${ }^{1}$ H. W. Barkema, J. De Buck, and K. Orsel \\ Department of Production Animal Health, Faculty of Veterinary Medicine, University of Calgary, Alberta, T2N 4N1 Canada
}

\begin{abstract}
Mycobacterium avium subspecies paratuberculosis (MAP), the etiologic agent of Johne's disease, a chronic progressive enteritis, is a common pathogen on dairy farms. Environmental sampling is frequently used to detect MAP-infected herds, because it does not require sample collection from individual animals. The objectives were to determine (1) location-specific odds of MAP-positive environmental sampling results and whether season or herd size affect results; (2) whether season and herd size affect the odds of collection of samples from certain locations; and (3) whether sample-set composition affects the odds of a positive set. Herd veterinarians, producer organization staff, and University of Calgary staff collected 5,588 samples on dairy farms in Alberta and Saskatchewan. Samples from sick-cow and calving pens and samples from dry-cow housing had lower odds of testing MAP-positive than lactating cowpen samples (odds ratio $=0.3$ and 0.4 , respectively). Samples collected from bedding packs and manure piles were less frequently MAP-positive than those collected from alleyways and lagoons, whereas samples collected in spring and summer more often tested MAP-positive than those collected in winter. Sample sets collected in summer more often included samples from all locations than samples collected in winter; therefore, we inferred that collectors had difficulties accessing certain areas in winter. Substitution of sample locations with others had minor effect on the sensitivity of sample sets containing 6 samples. However, set composition had an effect on the sensitivity of sample sets containing only 2 samples. In that regard, whereas sets with 2 manurestorage-area samples detected $81 \%$ of farms with at least one positive environmental sample, sets with only dry, sick, or calving-pen samples detected only $59 \%$. Environmental samples should be collected from areas where manure from numerous cows accumulates and can be well mixed (e.g., alleyways and manure lagoons). Collection of samples should be performed in spring or
\end{abstract}

Received July 28, 2014.

Accepted September 29, 2014.

${ }^{1}$ Corresponding author: rwolf@ucalgary.ca summer when locations are easier to access and samples have higher odds for testing MAP-positive.

Key words: paratuberculosis, environmental samples, Mycobacterium avium subspecies paratuberculosis, Johne's disease

\section{INTRODUCTION}

Johne's disease is a chronic progressive enteritis caused by Mycobacterium avium ssp. paratuberculosis (MAP; Fecteau and Whitlock, 2010). This disease is present in most countries with modern dairy industry (Barkema et al., 2010). The bacterium is mainly transmitted fecal-orally, although intrauterine transmission and transmission through infected colostrum have been reported (Stabel, 2008; Whittington and Windsor, 2009). Even before the onset of clinical symptoms, affected animals have lower milk production, increased risk of being culled, and decreased slaughter value (Hendrick et al., 2005; Raizman et al., 2009).

Culture of environmental samples is a relatively cheap, accurate, and reliable method for detection of MAP-infected herds (Raizman et al., 2004; Lombard et al., 2006; Aly et al., 2009; Lavers et al., 2013). Because the laboratory test method used for these samples is a direct pathogen-detection assay, it is commonly assumed that false-positive results are rare (Whitlock et al., 2000; Nielsen and Toft, 2008). Because of this advantage in accuracy and because environmental sampling does not require sample collection from individual animals, it is used in various regional and national MAPcontrol programs (Whitlock, 2010; Atlantic Johne's Disease Initiative, 2011; Wolf et al., 2014b). The most commonly used sampling protocol requires 6 samples collected at various locations on dairy farms (Berghaus et al., 2006). Samples collected from lactating-cow alleyways and manure storage areas are more frequently MAP-positive than those collected from sick-cow pens (Raizman et al., 2004; Lombard et al., 2006; Lavers et al., 2013). It is unknown, however, whether this apparent higher sensitivity is confounded by the origin of a sample within a pen. Sick-cow pen samples are often collected from straw packs, whereas lactating cow pen samples are most often collected from alleys. It is also 
unknown whether the type of manure storage (piles, pits, or lagoons) has an effect.

The effect of season on accuracy of environmental samples is controversial. Although a recent field study concluded season had no effect (Lavers et al., 2013) and a laboratory experiment concluded that long-term storage of samples at $-20^{\circ} \mathrm{C}$ did not affect MAP survival (Raizman et al., 2011), another laboratory experiment concluded that short-term storage at $-20^{\circ} \mathrm{C}$ reduced MAP survival (Khare et al., 2008). If subfreezing temperatures and frequent freeze-thaw cycles affect the survival of MAP bacteria, a seasonal effect can be anticipated for samples collected in certain geographical regions including Western Canada.

The commonly used sampling protocol requires sample collection from manure storage areas and close-up, sick, or calving pens if $\geq 2$ cows are present. However, collection of complete sample sets could be compromised in winter and on small farms. It is currently unknown whether the set composition affects sensitivity of the sample set.

The effect of herd size on the sensitivity of environmental culturing is unknown despite the fact that larger herds are more likely to be infected (Wells and Wagner, 2000; Pillars et al., 2009). It is plausible that the sensitivity of environmental samples is associated with the herd size. In that regard, assuming constant within-herd MAP prevalence, the odds of having at least one shedding cow in a pen is higher in large herds than in small herds because numerically, more animals are shedding. This effect should especially be present in dry, close-up, sick, and calving pens, because they are only populated by a few cows.

The objectives of this study were to determine (1) location-specific odds of MAP-positive environmental sampling results and whether season and herd size influence results; (2) whether season and herd size affect the odds of including at least one manure storage area sample and one dry, sick, or calving pen sample in a sample set; and (3) whether the sample-set composition affects the odds of a positive set.

\section{MATERIALS AND METHODS}

\section{Herds}

Environmental samples were collected on 601 dairy farms; most (70\%) samples were collected on 360 Alberta dairy farms voluntarily participating in the Alberta Johne's Disease Initiative (AJDI). The AJDI samples were collected annually by herd veterinarians, and farms could join and leave the program at any given time. Additionally, environmental samples were collected by University of Calgary personnel as part of other research projects on 75 farms not participating in the AJDI and 166 Saskatchewan dairy farms that were visited once either by an employee of the producer organization Saskatchewan Milk ( $\mathrm{n}=162$ farms) or by their herd veterinarian ( $\mathrm{n}=4$ farms). The study population included MAP-infected as well as uninfected herds. The true herd prevalence was estimated to be $68 \%$ for Alberta and $76 \%$ for Saskatchewan dairy farms, respectively (Wolf et al., 2014a).

\section{Sample Collection, Shipping, and Processing}

Sample collection was described in detail (Wolf et al., 2014a). In short, sample collectors were requested to collect 6 environmental samples, 2 samples in each of 3 predetermined locations: (1) manure concentration samples from lactating cow alleys and the end of scraper lines; (2) manure storage samples from lagoons, piles, or pits; and (3) if a minimum of 2 cows were present, cow concentration samples from drycow, close-up, calving, or sick-cow pens. Additional samples were collected from the other predetermined locations if locations did not qualify or were not accessible. Each sample contained at least 4 subsamples, resulting in mixed manure rather than manure from single cow pies. Samples were thoroughly mixed in ziplock bags and transferred into 90-mL nonsterile disposable containers. Before April 2011, sampling location was recorded on the containers. Thereafter, a standardized description sheet was used in which type of the animals in a pen (lactating cows, dry cows, or sick cows), pen type (tiestall, freestall, or loose housing), and sampling area (crossover alley, alley, exercise areas such as paddocks and milking parlor waiting areas, bedding pack, gutter, manure pit, manure pile, or lagoon) were recorded (Figure A1; Appendix). The comment section was used to describe sampling locations in detail. Samples were sent to the University of Calgary using express mail and stored at $4^{\circ} \mathrm{C}$. All samples were processed in fresh condition within $7 \mathrm{~d}$ after collection using a Trek ESP (Trek Diagnostic Systems, Cincinnati, OH) culture protocol with subsequent IS900 PCR confirmation (Vary et al., 1990; McKenna et al., 2005). Throughout the project, several improvements were implemented in the laboratory protocol, with the most important being the continuously increased use of $F 57$ quantitative (q)PCR; as of January 2012, F57 qPCR (Slana et al., 2008) was used on culture products if IS900 PCR resulted in undefined or inconclusive results. These changes likely resulted in improved sensitivity, because inconclusive IS900 PCR results were conservatively called negative, before the introduction of $F 5^{7}$ qPCR (Wolf et al., 2014a). 


\section{Statistical Analysis}

Analyses were conducted using STATA version 11 (Statacorp, College Station, TX). Results interpretation assumed almost perfect specificity of MAP culture (Whitlock et al., 2000; Nielsen and Toft, 2008). Higher odds for positive test results were therefore assumed to be caused by increased sensitivity instead of decreased specificity. The association between the outcomes and independent variables was examined using multilevel logistic regression to adjust for potential clustering within sample collectors, farms, and sample sets. The latent-variable approach was used to calculate intraclass correlation coefficients, a measure of the proportion of variance explained by various levels in the models (Vigre et al., 2004). Forward selection was used to select variables to include in the final models, and 2-way interactions were built to detect effect modification. A $P$-value of $\leq 0.05$ was considered significant, and a predictor change of $20 \%$ was used to detect confounding. Cluster-specific coefficients $\left(\beta^{\mathrm{SS}}\right)$ and odds ratios (OR) were presented for location, herd size, and season; they represented the OR of a specific subject experiencing the outcome in case of the presence of the exposure. In addition, population-averaged coefficients $\left(\beta^{\mathrm{PA}}\right)$ and OR were calculated using $\beta^{\mathrm{SS}}$ and the sum of the variance components in the various levels (ZU). The general formula for subject $i$ can be written as

$$
\beta^{\mathrm{PA}} \approx \beta^{\mathrm{SS}} / \sqrt{ }\left[1+0.346 \times \operatorname{variance}(\mathrm{ZU})_{i}\right] .
$$

The population-averaged OR represent the OR of experiencing the outcome in case of presence of the exposure across all subjects. It is recommended to use cluster-specific OR for variables that vary at the lowest level of a model (sample locations within a sample set) and population-averaged OR for coefficients that vary at higher levels (herd size does not vary within a sample set but differs between herds; Dohoo et al., 2009). The OR were not presented for project day and its square and cubic terms, because their interpretation would be complicated and not meaningful.

Environmental Samples. To identify predictors for environmental culture results, single-sample culture result was used as the outcome, whereas location, season, and herd size were included as independent variables. Herd size and season were included as categorical variables. Herd size and season were categorized in 50-cow $(<50,50-100,100-150,150-200,>200$ cows $)$ and 2-mo categories, respectively. To adjust for culture protocol improvements over the years, day of sample collection was used as a continuous variable (November 9, 2010 $=$ project $\mathrm{d} 1$; November $1,2013=$ project $\mathrm{d} 1,090$ ). Square and cubic terms were included to account for nonlinearity of the relationship. Sampling location was categorized into sites and areas within sites. Sites included the following categories: lactating cow pens; manure storage; and dry, sick, or calving pens. Areas within sites included alleys or gutters, exercise areas, bedding packs, and tiestalls for samples collected from lactating cow pens and dry, sick, or calving pens. It included lagoons, manure pits, and manure piles for manure-storage-area samples.

The first model estimated the effect of site, herd size, and season on the overall odds of a sample being MAP culture-positive, included all samples, and used sample site as the independent variable. Dry cow pen samples and sick-pen or calving-pen samples were separate categories. Because it can be expected that the effect of season and perhaps herd size on the odds of a MAPpositive sample is different among sample locations (manure storage samples are collected outside the barn, whereas lactating cow pen samples are collected inside; large herds may have more cows in sick-cow pens than small herds, and so on), separate models were built for each site. Area of collection was used as the independent variable.

Sampling Sites in a Sample Set. To determine whether herd size and season influenced the odds of collection of samples from certain sites, models were fit on a sample-set level. Only sample sets with sampling sites identified for all 6 samples were included in the analysis. Herd size and season were included as independent variables. Sample collector and farm were included as random effects. Three models were constructed for various outcomes: the first model estimated the odds of collection of a complete sample set containing at least one lactating cow housing sample, one manure storage area sample, and one dry-cow housing, sick-pen or calving-pen sample. The second model estimated the odds of a sample set including at least one manure storage area sample, and the third model estimated the odds of a sample set including at least one dry-cow housing, sick-pen, or calving-pen sample.

Test Results on Sample-Set Level. To determine whether the herd-level culture result was associated with the composition of a sample set, analysis was performed using sample sets with sampling sites identified for all 6 samples. The herd-level environmental sample result (no MAP culture-positive sample vs. $\geq 1$ positive sample within a sample set) was used as the outcome, whereas $\geq 1$ manure-storage-area sample collected (yes/no) and $\geq 1$ dry, sick, or calving pen sample collected (yes/no) were included as 2 independent variables. The analysis was adjusted for day of sample collection. Sample collector and farm were included as random effects.

Sample Sets with $<6$ Samples. The objective was to determine the relative sensitivity of a sample set with 
Table 1. Percentage of Mycobacterium avium ssp. paratuberculosis-positive environmental sample culture results collected at various locations, provinces, and sampling years [no. (\% positive samples)]

\begin{tabular}{|c|c|c|c|c|c|c|}
\hline \multirow[b]{2}{*}{ Location } & \multicolumn{3}{|c|}{ Year of sample collection } & \multicolumn{2}{|c|}{ Province } & \multirow[b]{2}{*}{ Total } \\
\hline & 2010,2011 & 2012 & 2013 & Alberta & Saskatchewan & \\
\hline \multicolumn{7}{|l|}{ Lactating cows } \\
\hline Alleys or gutters & $239(8)$ & $808(28)$ & $1,007(30)$ & $1,583(25)$ & $471(30)$ & $2,054(27)$ \\
\hline Exercise areas & $16(0)$ & $32(28)$ & $33(21)$ & $59(14)$ & $22(36)$ & $81(20)$ \\
\hline Bedding packs & $5(0)$ & $50(24)$ & $81(16)$ & $80(14)$ & $56(25)$ & $136(18)$ \\
\hline Tie stalls & $21(10)$ & $74(16)$ & $64(17)$ & $75(13)$ & $84(18)$ & $159(16)$ \\
\hline \multicolumn{7}{|l|}{ Manure storage } \\
\hline Pits & $142(11)$ & $207(25)$ & $229(32)$ & $516(24)$ & $62(24)$ & $578(24)$ \\
\hline Piles & $42(5)$ & $95(20)$ & $75(15)$ & $197(15)$ & $15(13)$ & $212(15)$ \\
\hline Lagoons & $88(18)$ & $144(33)$ & $124(40)$ & $332(31)$ & $24(38)$ & $356(32)$ \\
\hline \multicolumn{7}{|l|}{ Dry cows } \\
\hline Alleys or gutters & $9(0)$ & $18(44)$ & $73(26)$ & $90(24)$ & $10(50)$ & $100(27)$ \\
\hline Exercise areas & $3(0)$ & $35(17)$ & $38(24)$ & $41(10)$ & $35(31)$ & $76(20)$ \\
\hline Bedding packs & $12(0)$ & $75(17)$ & $123(15)$ & $124(15)$ & $86(14)$ & $210(15)$ \\
\hline \multicolumn{7}{|l|}{ Calving or sick } \\
\hline Alleys or gutters & $2(0)$ & $12(33)$ & $34(24)$ & $33(30)$ & $15(13)$ & $48(25)$ \\
\hline Exercise areas & $0(-)$ & $7(29)$ & $2(0)$ & $6(33)$ & $3(0)$ & $9(22)$ \\
\hline Bedding packs & $13(8)$ & $59(10)$ & $110(18)$ & $129(12)$ & $53(21)$ & $182(15)$ \\
\hline
\end{tabular}

less than 6 environmental samples compared with a set with 6 samples. Only sets that included 2 samples collected from lactating-cow housing, 2 samples collected from manure storage areas, and 2 samples collected from dry, sick, or calving pens were included in the analysis. Of those, only sample sets with at least one positive environmental sample were included. Sampling sites were selectively included in the analysis. For example, the relative sensitivity of 2 lactating cow housing samples described the proportion of sample sets with $\geq 1$ positive lactating cow housing sample among the sample sets with $\geq 1$ positive sample collected at any site. The analysis was repeated for all possible combinations of sampling sites including 2 to 6 samples.

\section{RESULTS}

\section{Environmental Samples}

A total of 655 sample sets were collected in the AJDI, 124 in other research projects in Alberta, and 166 in Saskatchewan. In total 5,588 samples were collected, of which 5,345 samples included sufficient information to identify their location, whereas 4,201 samples included sufficient information to identify the area of sample collection within the location.

A total of $620(25 \%)$ of 2,430 samples collected from lactating-cow housing were MAP culture-positive, whereas $284(24 \%)$ of 1,146 samples collected from manure storage areas, $73(19 \%)$ of 386 samples collected from dry-cow housing, and 41 (17\%) of 239 samples collected from calving or sick-cow pens were MAP culture-positive (Table 1). Although only $14 \%$ of the samples from herds with $<50$ cows were posi- tive, $42 \%$ of the samples from herds with $>200$ cows were MAP culture-positive (Table 2). Percentages of positive results fluctuated throughout the year, from $18 \%$ positive samples in September and October to $31 \%$ positive samples in March and April (Table 3). The number of collected samples per month increased over time because an increasing number of farms completed their second and third testing event (Figure 1).

Among samples taken within the same sample set, samples collected from dry-cow housing and samples collected from calving or sick-cow pens had lower odds of testing MAP-positive than samples taken from lactating-cow pens $(P<0.01$; Table 4$)$. Among manurestorage-area samples, samples collected from manure piles had lower odds of testing positive than samples collected from lagoons $(P=0.01)$. Culture results of lactating-cow housing did not differ for samples collected from alleyways or gutters, exercise areas, bedding packs, and tie-stalls $(P=0.27$; Table 5$)$. Dry-cow alleyway samples had higher odds of testing positive than dry-cow bedding-pack samples $(P=0.03)$ and calving or sick cow pen bedding-pack samples $(P=$ 0.01). The odds of testing MAP-positive were higher for all locations for larger herds compared with smaller herds $(P<0.01)$. Among all samples, samples collected between March and June had higher odds of testing positive than samples collected in January and February $(P=0.01)$. Evidence for seasonality was also present for samples collected in lactating cow housings and manure storage areas (Tables 4 and 5).

The percentage of variance explained by the sample collector was low for all samples but highest for samples taken in dry, sick, or calving pens (10\%). The variance explained by farm ranged from 0 to $34 \%$, whereas the 
Table 2. Percentage of Mycobacterium avium ssp. paratuberculosis-positive environmental sample culture results collected at various-sized herds [no. (\% positive samples)]

\begin{tabular}{lcccrr}
\hline Location & $<50$ cows & $50-100$ cows & $100-150$ cows & $150-200$ cows & $>200$ cows \\
\hline Lactating cows & & & & & \\
Alleys or gutters & $75(11)$ & $611(20)$ & $663(22)$ & $271(33)$ & $306(47)$ \\
Exercise areas & $5(20)$ & $26(8)$ & $28(29)$ & $7(43)$ & $9(50)$ \\
Bedding packs & $5(0)$ & $43(12)$ & $42(21)$ & $9(22)$ & $14(36)$ \\
Tie stalls & $43(23)$ & $62(15)$ & $25(12)$ & $4(0)$ & $1(0)$ \\
Manure storage & $12(8)$ & $139(20)$ & $218(25)$ & $88(27)$ & $95(28)$ \\
Pits & $24(4)$ & $77(17)$ & $68(16)$ & $16(19)$ & $25(12)$ \\
Piles & $10(20)$ & $85(18)$ & $119(23)$ & $71(42)$ & $63(56)$ \\
Lagoons & $1(0)$ & $10(1)$ & $29(34)$ & $15(47)$ & $12(50)$ \\
Dry cows & $7(57)$ & $1(0)$ & $18(11)$ & $10(30)$ & $8(25)$ \\
Alleys or gutters & $6(0)$ & $45(2)$ & $63(14)$ & $28(11)$ & $33(42)$ \\
Exercise areas & $2(0)$ & $10(1)$ & $10(20)$ & $11(36)$ & $15(33)$ \\
Bedding packs & $3(0)$ & $1(0)$ & $2(0)$ & $2(50)$ & $1(100)$ \\
Calving or sick & $6(0)$ & $45(2)$ & $57(12)$ & $24(13)$ & $43(35)$ \\
Alleys or gutters & $199(14)$ & $1,155(17)$ & $1,342(21)$ & $556(31)$ & $620(42)$ \\
Exercise areas & & & & \\
Bedding packs & & & & \\
Total & & & & \\
\hline
\end{tabular}

variance explained by sample set ranged from 40 to $54 \%$.

\section{Sampling Sites in a Sample Set}

A total of $841(90 \%)$ sample sets had sufficient information to identify the sampling site of all 6 samples within a set (Table 6). Overall, $423(51 \%)$ of the 841 sample sets were identified as complete sample sets, meaning that they included at least one lactating cow pen sample; one manure storage area sample; and one dry, calving, or sick cow pen sample. The probability of a complete environmental sample set differed among months of the year and was higher between March and June than in January and February $(P<0.01$; Table 7 ,
Figure 2). Dry, sick, or calving pen samples were also more often collected on farms with $>150$ cows than on farms with $<150$ cows $(P<0.01$; Table 7$)$.

The percentage of variance explained by the sample collectors differed among various logistic regression models and ranged from 40 to $48 \%$. The percentage of variance explained by the farm ranged from 2 to $5 \%$.

\section{Test Results on Sample-Set Level}

A total of 192 (45\%) of 423 complete and 192 (46\%) of 418 incomplete sample sets had at least one sample that was MAP culture-positive (Table 6). Herd-level result was not associated with the inclusion of manure storage area and dry, sick, or calving pen samples in a

Table 3. Percentage of Mycobacterium avium ssp. paratuberculosis-positive environmental sample results collected in various months [no. (\% positive samples)]

\begin{tabular}{lrrrrrr}
\hline Location or area & Jan-Feb & Mar-Apr & May-Jun & Jul-Aug & Sep-Oct & Nov-Dec \\
\hline Lactating cows & & & & & & \\
$\quad$ Alleys or gutters & $418(24)$ & $309(34)$ & $615(29)$ & $245(27)$ & $243(21)$ & $224(22)$ \\
Exercise areas & $18(33)$ & $5(20)$ & $18(6)$ & $17(12)$ & $12(17)$ & $11(36)$ \\
Bedding packs & $38(21)$ & $17(18)$ & $29(14)$ & $12(17)$ & $13(8)$ & $27(26)$ \\
Tie stalls & $34(12)$ & $23(9)$ & $20(25)$ & $0(-)$ & $31(13)$ & $51(20)$ \\
Manure storage & & & & & \\
Pits & $46(18)$ & $114(33)$ & $178(28)$ & $76(16)$ & $55(11)$ & $71(28)$ \\
Piles & $70(20)$ & $48(21)$ & $22(9)$ & $18(6)$ & $38(16)$ \\
Lagoons & $14(29)$ & $27(44)$ & $33(15)$ & $8(25)$ & $9(0)$ & $9(44)$ \\
Dry cows & $4(25)$ & $6(17)$ & $19(32)$ & $19(5)$ & $17(18)$ & $11(27)$ \\
Alleys or gutters & $62(15)$ & $30(27)$ & $46(4)$ & $28(14)$ & $22(18)$ & $22(18)$ \\
Exercise areas & $10(10)$ & $6(17)$ & $11(27)$ & $13(46)$ & $4(25)$ & $4(0)$ \\
Bedding packs & $1(0)$ & $2(50)$ & $2(0)$ & $0(-)$ & $4(25)$ & $0(-)$ \\
Calving or sick & $44(16)$ & $40(25)$ & $43(16)$ & $22(0)$ & $9(11)$ & $24(8)$ \\
Alleys or gutters & $780(20)$ & $663(31)$ & $1,218(26)$ & $526(22)$ & $505(18)$ & $509(23)$ \\
Exercise areas & & & & & \\
Bedding packs & & & & & \\
Total & & & & & \\
\hline
\end{tabular}




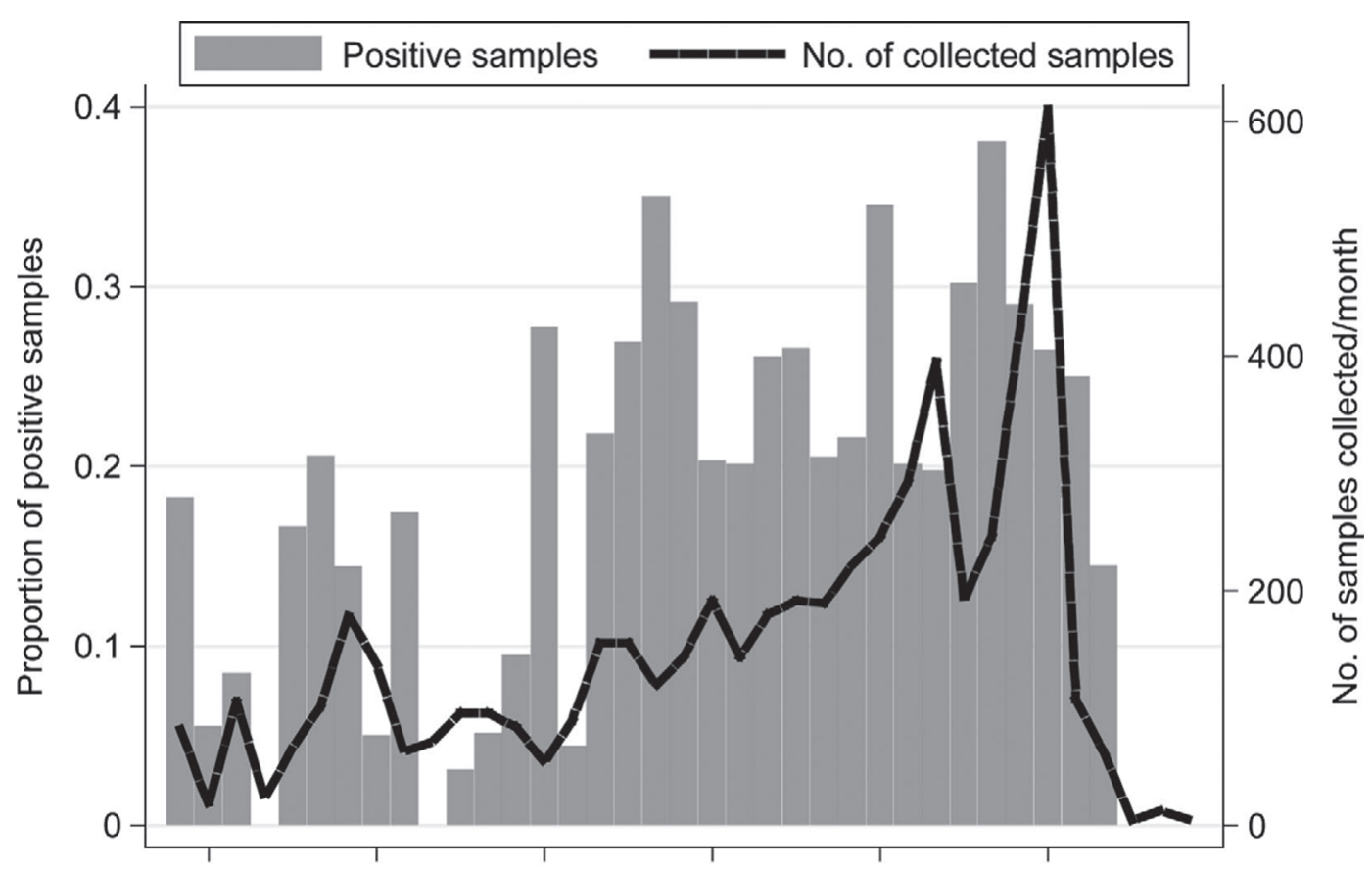

Dec. 2010 Jun. 2011 Dec. 2011 Jun. 2012 Dec. 2012 Jun. 2013

Figure 1. Temporal pattern of the monthly proportion of environmental samples testing positive for Mycobacterium avium ssp. paratuberculosis, and the number of samples collected in Alberta and Saskatchewan.

sample set (lowest $P=0.51$, results not shown, because the predictor estimates for herd size, season, and project day were very similar to the estimates presented in Tables 4 and 5).

\section{Sample Sets with <6 Samples}

A total of 219 sample sets included 2 lactating cow housing, 2 manure storage, and 2 dry, sick, or calving pen samples; 100 (46\%) of these sample sets had at least one MAP-positive sample. Among the 100 test-positive sets, $81 \%$ would have tested positive if only 2 manure storage area samples had been collected, whereas $59 \%$ would have tested positive if only 2 dry, sick, or calving pen samples had been collected (Table 8).

\section{DISCUSSION}

Environmental samples were significantly more likely to be MAP culture-positive if collected from lactating cow pens and manure storage areas compared with dry, calving, or sick cow pens, which confirms earlier reports (Raizman et al., 2004; Lombard et al., 2006; Lavers et al., 2013). The area of sample collection was important; alleyways and manure lagoons were more likely to test positive than bedding packs and manure piles. Selection of locations in a sample set was more important for sampling protocols that included only 2 samples, although it did not have a high effect on the sensitivity of a sample set that included 5 or 6 samples, which gives sample collectors the required flexibility to collect samples on small farms and in winter when certain locations are not available or accessible.

As reported earlier, the odds of testing MAP-positive and therefore the sensitivity of environmental samples were lower for samples collected in dry, calving, and sick pens compared with samples collected in lactating-cow housing and manure storage, which may appear counter intuitive because clinical Johne's disease cases should be housed in sick-cow pens (Raizman et al., 2004; Lombard et al., 2006; Lavers et al., 2013). One explanation is that farmers are aware of the risk of MAP transmission through clinical cases and remove those animals soon after detection, while leaving subclinical, shedding animals in the lactating cow herd. Another explanation is the number of cows whose manure was included in a sample; in that regard, more cows contribute to the manure in a lactating cow pen or manure lagoon than to the manure in a sick-cow pen. Considering that most infected herds have low within-herd prevalences and only approximately 30 to $40 \%$ of infected cows actually shed the bacterium (Whitlock et al., 2000; Barkema et al., 2010), chances are high that a sick cow-pen sample tests negative, because no cow in the pen sheds MAP. A third reason for lower odds of a MAP-positive test result for dry-cow housing and calving and sick pens 
Table 4. Final logistic regression models on the association between the Mycobacterium avium ssp. paratuberculosis environmental sample culture result and sample location, herd size, and season (all samples; samples collected from manure storage areas)

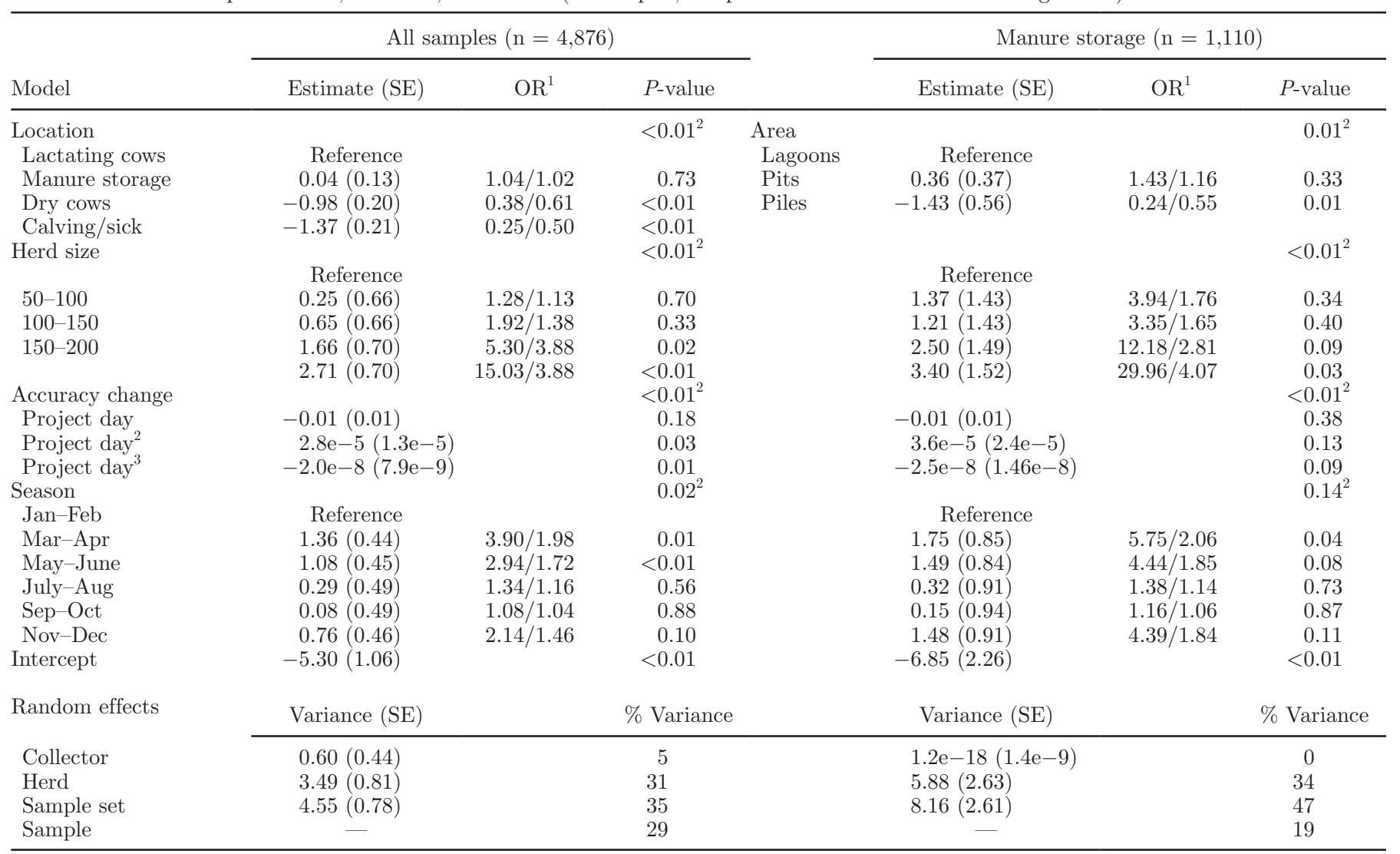

${ }^{1}$ Cluster-specific odds ratio (OR)/approximated population-averaged (marginal) OR.

${ }^{2}$ Wald $P$-value for the coefficient; values in parentheses refer to $P$-values for variables not included in the final model.

is the area of sample collection. Sick-cow pens are often straw packs; therefore, a high proportion of these samples are bedding-pack samples (76\% of the sick cow pen samples vs. $6 \%$ of the lactating cow-pen samples). Because of the dryness of the material (which is even more increased through the generally drier consistency of dry-cow manure) and high straw content, proper mixing of subsamples was apparently compromised, perhaps reducing odds of positive samples collected from bedding packs. In contrast, this relationship was not evident for lactating cow samples, possibly because of more cows in the pens. However, only a few lactating cow pen samples were collected from bedding packs and an actual association could have been missed because of low sample size.

The lower odds for MAP-positive results of manure pile samples compared with pits and lagoons can be explained with the same reasons as described above. In that regard, in Western Canada, most lactating cows are housed in freestalls with liquid manure production, whereas dry, calving, and sick cows are often housed on straw packs. Consequently, manure piles only contain the manure of dry, calving, and sick cows, reducing the number of cows contributing to a sample. The degree of manure mixture is also reduced, because of the high straw content in a manure-pile sample.

Samples collected in spring had higher odds of testing MAP-positive than samples collected in winter. This provided evidence for an effect of season on environmental sample results, apparently because of differences in temperature and humidity affecting the viability of MAP bacteria in excreted manure before sample collection. The use of direct PCR methods instead of culture would likely be an alternative, because PCR does not require viable bacteria in the sample. However, further research is needed to determine the accuracy of direct PCR in environmental samples.

Samples collected from larger herds were more likely to test MAP-positive than samples collected from smaller herds. One reason is the higher risk of MAP infection for large herds compared with small herds because of differences in management and more purchased cattle (Wells and Wagner, 2000; Pillars et al., 2009). Because the effect of herd size was consistent throughout locations, this study did not provide any evidence for an effect of herd size on the accuracy of environmental 
Table 5. Final logistic regression models on the association between the Mycobacterium avium ssp. paratuberculosis environmental sample culture result and sample location, herd size, and season (samples collected in lactating cow pens and dry/calving/sick cow pens)

\begin{tabular}{|c|c|c|c|c|c|c|c|}
\hline Model & \multicolumn{3}{|c|}{ Lactating cows $(\mathrm{n}=2,713)$} & & \multicolumn{3}{|c|}{ Dry/calving/sick cows $(\mathrm{n}=568)$} \\
\hline $\begin{array}{l}\text { Area } \\
\text { Alleys/gutters } \\
\text { Exercise areas } \\
\text { Bedding packs } \\
\text { Tie-stalls }\end{array}$ & NS & & $(0.27)^{1}$ & $\begin{array}{l}\text { Area }^{2} \\
\text { DC alleys/gutters } \\
\text { DC exercise areas } \\
\text { DC bedding packs } \\
\text { CS alleys/gutters } \\
\text { CS exercise areas } \\
\text { CS bedding packs }\end{array}$ & $\begin{array}{r}\text { Reference } \\
-0.54(0.73) \\
-1.55(0.63) \\
-0.83(0.79) \\
0.34(1.43) \\
-1.69(0.65)\end{array}$ & $\begin{array}{l}0.58 / 0.74 \\
0.21 / 0.42 \\
0.44 / 0.63 \\
1.40 / 1.21 \\
0.18 / 0.39\end{array}$ & $\begin{array}{l}0.07^{3} \\
0.46 \\
0.01 \\
0.29 \\
0.81 \\
0.01\end{array}$ \\
\hline Herd size & Reference & & $<0.01^{3}$ & & Reference & & $<0.01$ \\
\hline $\begin{array}{l}50-100 \\
100-150 \\
150-200\end{array}$ & $\begin{array}{l}0.17(0.83) \\
0.32(0.83) \\
1.54(0.89) \\
2.97(0.89)\end{array}$ & $\begin{array}{r}1.19 / 1.08 \\
1.38 / 1.15 \\
4.66 / 1.93 \\
19.49 / 3.56\end{array}$ & $\begin{array}{r}0.84 \\
0.70 \\
0.08 \\
<0.01\end{array}$ & & $\begin{array}{r}-0.41(1.25) \\
1.42(1.28) \\
1.88(1.31) \\
3.31(1.39)\end{array}$ & $\begin{array}{r}0.66 / 0.80 \\
4.14 / 2.21 \\
6.55 / 2.86 \\
27.39 / 6.35\end{array}$ & $\begin{array}{l}0.75 \\
0.27 \\
0.15 \\
0.02\end{array}$ \\
\hline Random effects & Variance (SE) & & $\%$ Variance & & Variance (SE) & & \% Variance \\
\hline $\begin{array}{l}\text { Collector } \\
\text { Herd } \\
\text { Sample set } \\
\text { Sample }\end{array}$ & $\begin{array}{l}1.09(0.79) \\
5.31(1.37) \\
6.50(1.33) \\
-\end{array}$ & & $\begin{array}{r}7 \\
33 \\
40 \\
20\end{array}$ & & $\begin{array}{l}1.17(0.94) \\
2.3 \mathrm{e}-8(8.5 \mathrm{e}-3) \\
5.2(2.5) \\
\quad-\end{array}$ & & $\begin{array}{r}12 \\
0 \\
54 \\
34\end{array}$ \\
\hline
\end{tabular}

${ }^{1}$ Cluster-specific odds ratio (OR)/approximated population-averaged (marginal) OR.

${ }^{2} \mathrm{DC}=$ dry-cow pens; $\mathrm{CS}=$ calving, sick-cow pens.

${ }^{3}$ Wald $P$-value for the coefficient; values in parentheses refer to $P$-values for variables not included in the final model.

samples collected at specific locations. However, should higher in those herds, because within-herd prevalence larger herds have higher within-herd MAP prevalence, is positively associated with herd sensitivity (Lavers et the accuracy of environmental sampling would be al., 2013).

Table 6. Locations of environmental sample collection for dairy farms in Alberta and Saskatchewan [no. of sample sets (\% sample sets with at least one positive sample)]

\begin{tabular}{|c|c|c|c|c|c|c|c|c|c|c|c|}
\hline $\mathrm{LC}^{1}$ & $\mathrm{MS}^{1}$ & $\mathrm{DC}^{1}$ & $\mathrm{CS}^{1}$ & \multicolumn{3}{|c|}{ Herd size (cows) } & \multicolumn{4}{|c|}{ Season } & Total \\
\hline+ & + & + & + & $24(29)$ & $43(27)$ & $35(60)$ & $20(35)$ & $51(45)$ & $17(47)$ & $15(40)$ & $103(43)^{2}$ \\
\hline+ & - & + & + & $11(27)$ & $8(63)$ & $13(77)$ & $17(59)$ & $6(100)$ & $8(25)$ & $8(50)$ & $39(56)$ \\
\hline- & + & + & + & $1(0)$ & $0(-)$ & $0(-)$ & $1(-)$ & $0(-)$ & $0(-)$ & $0(-)$ & $1(0)$ \\
\hline+ & + & - & + & $35(57)$ & $43(37)$ & $71(62)$ & $43(49)$ & $66(62)$ & $22(45)$ & $21(52)$ & $152(55)^{2}$ \\
\hline+ & - & - & + & $9(44)$ & $5(20)$ & $14(64)$ & $19(63)$ & $4(25)$ & $1(100)$ & $5(20)$ & $29(52)$ \\
\hline- & + & + & - & $1(100)$ & $0(-)$ & $1(100)$ & $0(-)$ & $2(100)$ & $0(-)$ & $0(-)$ & $2(100)$ \\
\hline+ & + & - & - & $80(33)$ & $88(39)$ & $48(56)$ & $53(30)$ & $75(49)$ & $46(37)$ & $46(41)$ & $220(40)$ \\
\hline+ & - & - & - & $31(32)$ & $21(52)$ & $6(67)$ & $14(36)$ & $27(44)$ & $6(33)$ & $18(50)$ & $65(43)$ \\
\hline - & + & - & - & $0(-)$ & $1(100)$ & $0(-)$ & $0(-)$ & $1(100)$ & $0(-)$ & $0(-)$ & $1(100)$ \\
\hline Total & & & & $268(36)$ & $274(41)$ & $246(59)$ & $224(44)$ & $316(51)$ & $144(39)$ & $157(43)$ & $841(46)$ \\
\hline
\end{tabular}

${ }^{1} \mathrm{LC}=$ lactating-cow pen, $\mathrm{MS}=$ manure storage area, $\mathrm{DC}=$ dry-cow pen, $\mathrm{CS}=$ calving, sick pens.

${ }^{2}$ Complete sample sets with at least one lactating-cow housing, one manure storage area, and one dry cow housing or sick or calving-pen sample. 
Table 7. Final logistic regression models for the association between the completeness of an environmental sample set and season and herd size $(\mathrm{n}=841$ sample sets)

\begin{tabular}{|c|c|c|c|c|c|c|c|c|c|c|c|c|c|c|c|}
\hline \multirow[b]{2}{*}{ Parameter } & \multicolumn{5}{|c|}{ Complete sets } & \multicolumn{5}{|c|}{ Manure storage areas } & \multicolumn{5}{|c|}{ Dry, calving, sick pens } \\
\hline & $\begin{array}{l}\text { Est. }^{1} \\
\text { (SE) }\end{array}$ & $\mathrm{OR}^{2}$ & $P$-value & $\begin{array}{l}\text { Var. }^{3} \\
\text { (SE) }\end{array}$ & $\begin{array}{c}\% \\
\text { Var. }\end{array}$ & $\begin{array}{l}\text { Est. } \\
\text { (SE) }\end{array}$ & $\mathrm{OR}^{2}$ & $P$-value & $\begin{array}{l}\text { Var. } \\
\text { (SE) }\end{array}$ & $\begin{array}{c}\% \\
\text { Var. }\end{array}$ & $\begin{array}{l}\text { Est. } \\
\text { (SE) }\end{array}$ & $\mathrm{OR}^{2}$ & $P$-value & $\begin{array}{l}\text { Var. } \\
\text { (SE) }\end{array}$ & $\begin{array}{c}\% \\
\text { Var. }\end{array}$ \\
\hline Herd size & NS & & $(0.24)^{4}$ & & & NS & & $(0.91)^{4}$ & & & & & $<0.01^{4}$ & & \\
\hline $\begin{array}{l}50-100 \\
100-150 \\
150-200\end{array}$ & & & & & & & & & & & $\begin{array}{l}\text { Reference } \\
0.01(0.51) \\
0.13(0.51) \\
1.06(0.55) \\
1.01(0.56)\end{array}$ & $\begin{array}{l}1.01 / 1.01 \\
1.14 / 1.09 \\
2.89 / 2.05 \\
2.75 / 1.99\end{array}$ & $\begin{array}{l}0.96 \\
0.80 \\
0.06 \\
0.07\end{array}$ & & \\
\hline Season & Beference & & $<0.01^{4}$ & & & Beference & & $0.02^{4}$ & & & Beference & & $<0.01$ & & \\
\hline Mar-Apr & $1.17(0.34)$ & $3.22 / 2.29$ & $<0.01$ & & & $0.58(0.37)$ & $1.79 / 1.51$ & 0.11 & & & $\begin{array}{l}\text { Kererence } \\
0.95(0.39)\end{array}$ & $2.59 / 1.91$ & 0.02 & & \\
\hline May-Jun & $1.03(0.31)$ & $2.80 / 2.07$ & $<0.01$ & & & $0.65(0.33)$ & $1.92 / 1.59$ & 0.05 & & & $0.50(0.36)$ & $1.65 / 1.40$ & 0.16 & & \\
\hline Jul-Aug & $0.34(0.35)$ & $1.40 / 1.27$ & 0.34 & & & $0.86(0.41)$ & $2.36 / 1.85$ & 0.04 & & & $-0.07(0.41)$ & $0.93 / 0.95$ & 0.87 & & \\
\hline Sep-Oct & $0.65(0.34)$ & $1.92 / 1.58$ & 0.06 & & & $1.30(0.43)$ & $3.67 / 2.53$ & $<0.01$ & & & $-0.44(0.41)$ & $0.64 / 0.74$ & 0.28 & & \\
\hline Nov-Dec & $-0.45(0.33)$ & $0.64 / 0.73$ & 0.16 & & & $-0.04(0.33)$ & $0.96 / 0.97$ & 0.90 & & & $-0.83(0.39)$ & $0.44 / 0.57$ & 0.03 & & \\
\hline Intercept & $-0.29(0.33)$ & & 0.33 & & & $1.85(0.40)$ & & $<0.01$ & & & $0.52(0.62)$ & & 0.40 & & \\
\hline \multicolumn{16}{|c|}{ Random effect } \\
\hline Collector & & & & $2.65(0.94)$ & 43 & & & & $2.49(1.00)$ & 41 & & & & $3.22(1.13)$ & 48 \\
\hline Herd & & & & $0.25(0.45)$ & 4 & & & & $0.27(0.56)$ & 4 & & & & $0.15(0.43)$ & 2 \\
\hline Sample set & & & & - & 53 & & & & - & 55 & & & & - & 50 \\
\hline
\end{tabular}

${ }^{1}$ Est. = estimate.

${ }^{2}$ Cluster-specific odds ratio (OR)/approximated population-averaged (marginal) OR.

D) Var. = variance.

글 ${ }^{4}$ Wald $P$-value for the coefficient; values in parentheses refer to $P$-values for variables not included in the final model. 


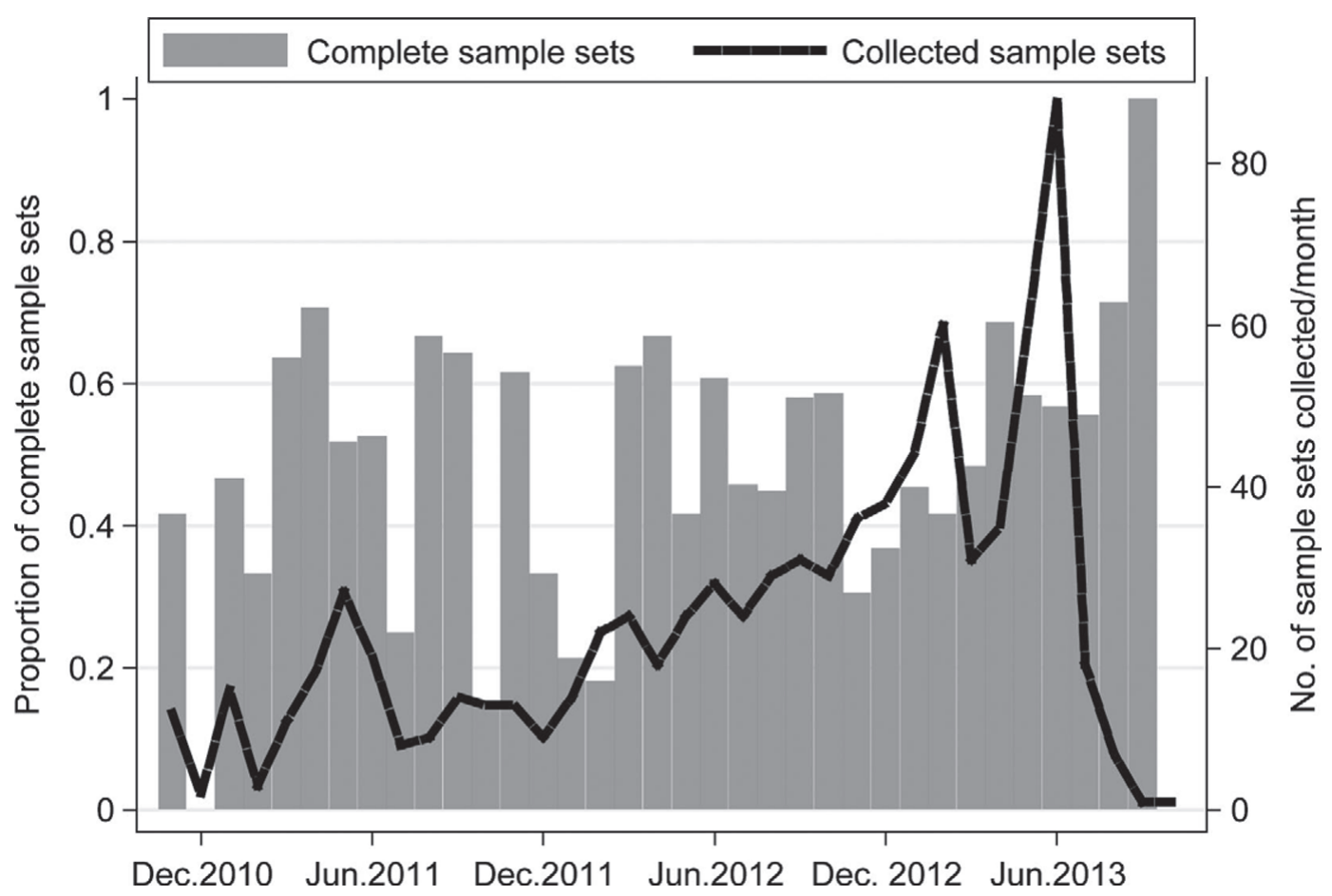

Figure 2. Temporal pattern of the proportion of complete environmental sample sets (sample sets with at least one lactating cow-pen, one manure-storage-area, and one dry, sick, or calving-pen sample), and the number of sample sets collected in Alberta and Saskatchewan.

Table 8. Percentage of Mycobacterium avium ssp. paratuberculosispositive environmental sample sets with various numbers of samples collected at various locations $(\mathrm{n}=100$ sample sets with $\geq 1$ positive environmental sample)

\begin{tabular}{|c|c|c|c|c|}
\hline Item & $\mathrm{LC}^{1}$ & $\mathrm{MS}^{1}$ & $\mathrm{DCS}^{1}$ & $\begin{array}{c}\% \text { Positive sets } \\
(95 \% \text { CI })\end{array}$ \\
\hline \multicolumn{5}{|c|}{2 Samples } \\
\hline & 0 & 2 & 0 & $81(73-89)$ \\
\hline & 2 & 0 & 0 & $70(61-78)$ \\
\hline & 0 & 0 & 2 & $59(49-69)$ \\
\hline & 1 & 1 & 0 & $77(69-85)$ \\
\hline & 1 & 0 & 1 & $62(52-72)$ \\
\hline & 0 & 1 & 1 & $72(63-81)$ \\
\hline \multicolumn{5}{|c|}{3 Samples } \\
\hline & $\begin{array}{l}1 \\
0\end{array}$ & $\begin{array}{l}2 \\
2\end{array}$ & $\begin{array}{l}0 \\
1\end{array}$ & $\begin{array}{l}87(71-87) \\
85(78-92)\end{array}$ \\
\hline & 1 & 1 & 1 & $82(74-90)$ \\
\hline & 2 & 1 & 0 & $86(79-93)$ \\
\hline & 2 & 0 & 1 & $74(65-83)$ \\
\hline & 0 & 1 & 2 & $82(74-90)$ \\
\hline & 1 & 0 & 2 & $72(63-81)$ \\
\hline 4 Samples & 0 & 2 & 2 & $93(88-98)$ \\
\hline & 1 & 2 & 1 & $90(84-96)$ \\
\hline & 2 & 2 & 0 & $93(88-98)$ \\
\hline & 2 & 1 & 1 & $89(83-95)$ \\
\hline & 2 & 0 & 2 & $81(73-89)$ \\
\hline & 1 & 1 & 2 & $88(82-94)$ \\
\hline 5 Samples & 2 & 2 & 1 & $95(91-99)$ \\
\hline & 2 & 1 & 2 & $94(89-98)$ \\
\hline & 1 & 2 & 2 & $96(92-100)$ \\
\hline
\end{tabular}

${ }^{1}$ Number of samples collected at LC $=$ lactating-cow housing; MS $=$ manure storage; DCS $=$ dry-cow, calving, and sick pens.
The variance components estimated by the different logistic regression models provide evidence for clustering in the data set. A very low proportion of variance $(<10 \%)$ in the odds of a positive sample result was explained by the sample collector, which confirmed high repeatability of results among collectors (Aly et al., 2009). Much variance was clustered within farms (31\% for all samples), reflecting differences in withinherd MAP prevalence among farms. However, it was noteworthy that the results for dry cow housing and calving and sick cow pen samples were not clustered within farms but instead tended to have a higher residual proportion of variance at the lowest level (54\%), perhaps because of lower repeatability of samples collected at these locations, but might also be caused by different predictors included in the final logistic regression model, because it did not include season and project day.

Models estimating the composition of sample sets had a different distribution of variance components; although 40 to $48 \%$ of the variance in the outcome was explained by the sample collector, only 2 to $5 \%$ was explained by the farm. The high proportion of variance explained by the collector provided evidence that collection of certain samples was a decision made by sampling personnel. One common reason for incomplete sample sets was not collecting manure-storage-area samples. In particular, half-empty manure pits posed a challenge 
because the surface could not be reached, and entering the pit would have posed an unacceptable safety risk. A possible solution is the use of commercially available golf ball retriever sticks. Many veterinarians and all University of Calgary personnel used these sticks with an attached ziplock bag to collect samples from pits. Fortunately, the risk of cross contamination between samples was low, because sample material did not come in contact with the stick. Solutions like this could have been communicated during follow-up workshops for collectors, which would have been expected to increase the number of complete sample sets.

The composition of sample sets did not only depend on the sample collectors but also on herd size and the season. Sample sets were more likely to be complete if collected in spring and summer, because lagoons and pits could not be sampled in winter because they were covered with ice and snow. Some farms had manure pits inside, but in many cases, additional samples were collected from lactating-cow pens. Collection of samples from outside dry-cow pens was also compromised by low temperatures, snow cover, and frozen material. An additional factor for the collection of dry, calving, and sick cow pen samples was herd size. Because collectors were instructed to only collect samples from pens containing $\geq 2$ cows, the probability was higher on small herds that pens did not qualify.

The composition of sample sets did not have an effect on the odds of having at least 1 positive sample in the sample set with 6 samples. Sets where locations were replaced with others did not have lower odds of testing positive. However, if a lower number of samples were collected within a set, the location of sample collection was more important. Although $81 \%$ of the 100 positive sets were detected with 2 manure storage area samples, only $59 \%$ were detected with 2 dry cow housing and sick or calving pen samples, making 2 manure storage area samples an apparently cost-effective sampling protocol. The proportion of positive sets was obviously driven by the accuracy of the samples included in a set, because manure storage area samples were more accurate than sick cow pen samples. Therefore, if a set only includes 2 samples, all samples should be collected from locations with a high sensitivity. In contrast, if 4,5 , or 6 samples are included in a set, the effect of the accuracy of a single sample on the accuracy of the whole set decreases, which supports the suggestion that sample locations can be replaced with others if they are not accessible.

The present study provided insight regarding how to optimize a one-time sampling protocol with a maximum of 6 environmental samples. It also provided estimates on the reduction of accuracy if $<6$ samples were collected. In addition, the accuracy of repeated testing with 6 environmental samples per test event is well documented (Khol et al., 2009; Lavers et al., 2013; Wolf et al., 2014a). It is unknown whether the accuracy increases if $>6$ samples are collected per set. If so, uncertainty around results of prevalence studies would decrease, and precision of within-herd prevalence estimation would likely increase. Also, knowledge gaps exist around sampling intervals and number of samples taken per test event if repeated testing is used to monitor progress in control programs, and to increase certainty around freedom of MAP in test-negative herds. These questions should be addressed within a longitudinal study incorporating estimation of withinherd prevalence and collection of a large number of environmental samples in short intervals.

\section{CONCLUSIONS}

To ensure high sensitivity of environmental sampling, sample sets should only include samples collected from areas where manure from several cows can be well mixed; those include lactating-cow alleys and gutters over sick or calving pen bedding packs, and lagoons and pits instead of piles. Samples should be collected in spring and summer instead of in winter, because manure storage areas and outdoor pens are easier to access and culture of environmental samples is more accurate. Replacing sample locations with others had an effect on the sensitivity of sample sets containing only a small number of samples but had only a minor effect on the sensitivity of a set containing 6 environmental samples.

\section{ACKNOWLEDGMENTS}

The authors thank the producer organizations Alberta Milk and SaskMilk for their assistance with farm recruitment and sample collection. This study was funded by Alberta Milk, the Alberta Livestock and Meat Agency (ALMA), and Agriculture and Agri-Food Canada through the Canadian Agricultural Adaptation Program (CAAP) delivered by the Agriculture Council of Saskatchewan.

\section{REFERENCES}

Aly, S. S., R. J. Anderson, R. H. Whitlock, T. L. Fyock, S. McAdams, J. M. Adaska, J. Jiang, and I. A. Gardner. 2009. Reliability of environmental sampling to quantify Mycobacterium avium subspecies paratuberculosis on California free-stall dairies. J. Dairy Sci. 92:3634-3642.

Atlantic Johne's Disease Initiative. 2011. Atlantic Johne's Disease Initiative. Accessed July 3, 2014. http://www.atlanticjohnes.ca/.

Barkema, H. W., J. W. Hesselink, S. L. B. McKenna, A. Benedictus, and H. Groenendaal. 2010. Global prevalence and economics of infection with Mycobacterium avium ssp. paratuberculosis in ruminants. Pages 10-21 in Paratuberculosis-Organism, Disease and Control. M. A. Behr and D. M. Collins, ed. CABI, Wallingford, UK. 
Berghaus, R. D., T. B. Farver, R. J. Anderson, C. C. Jaravata, and I. A. Gardner. 2006. Environmental sampling for detection of $\mathrm{Myco-}$ bacterium avium ssp. paratuberculosis on large California dairies. J. Dairy Sci. 89:963-970.

Dohoo, I. R., S. W. Martin, and H. Stryhn. 2009. Mixed models for discrete data. Pages 579-606 in Veterinary Epidemiologic Research. M. S. McPike, ed. Atlantic Vet. College, Charlottetown, Canada.

Fecteau, M. E., and R. H. Whitlock. 2010. Paratuberculosis in cattle. Pages 144-156 in Paratuberculosis - Organism, Disease and Control. M. A. Behr and D. M. Collins, ed. CABI, Wallingford, UK.

Hendrick, S. H., D. F. Kelton, K. E. Leslie, K. D. Lissemore, M. Archambault, and T. F. Duffield. 2005. Effect of paratuberculosis on culling, milk production, and milk quality in dairy herds. J. Am. Vet. Med. Assoc. 227:1302-1308.

Khare, S., L. G. Adams, J. Osterstock, A. Roussel, and L. David. 2008. Effects of shipping and storage conditions of fecal samples on viability of Mycobacterium paratuberculosis. J. Clin. Microbiol. 46:1561-1562

Khol, J. L., M. Vill, M. Dunser, E. Geisbauer, A. Tichy, and W. Baumgartner. 2009. Environmental sampling, a new approach in diagnosis and surveillance of paratuberculosis in Austrian cattle herds. Wien. Tierarztl. Monatsschr. 96:279-285.

Lavers, C. J., S. L. B. McKenna, I. R. Dohoo, H. W. Barkema, and G. P. Keefe. 2013. Evaluation of environmental fecal culture for $M y$ cobacterium avium subspecies paratuberculosis detection in dairy herds and association with apparent within-herd prevalence. Can. Vet. J. 54:1053-1060.

Lombard, J. E., B. A. Wagner, R. L. Smith, B. J. McCluskey, B. N. Harris, J. B. Payeur, F. B. Garry, and M. D. Salman. 2006. Evaluation of environmental sampling and culture to determine Mycobacterium avium subspecies paratuberculosis distribution and herd infection status on US dairy operations. J. Dairy Sci. 89:4163-4171.

McKenna, S. L. B., G. P. Keefe, H. W. Barkema, and D. C. Sockett. 2005. Evaluation of three ELISAs for Mycobacterium avium ssp. paratuberculosis using tissue and fecal culture as comparison standards. Vet. Microbiol. 110:105-111.

Nielsen, S. S., and N. Toft. 2008. Ante mortem diagnosis of paratuberculosis: A review of accuracies of ELISA, interferon- $\gamma$ assay and faecal culture techniques. Vet. Microbiol. 129:217-235.

Pillars, R. B., D. L. Grooms, J. A. Woltanski, and E. Blair. 2009 Prevalence of Michigan dairy herds infected with Mycobacterium avium subspecies paratuberculosis as determined by environmental sampling. Prev. Vet. Med. 89:191-196.

Raizman, E. A., L. A. Espejo, and S. J. Wells. 2011. Long-term survival of Mycobacterium avium ssp. paratuberculosis in fecal samples obtained from naturally infected cows and stored at -18 degrees $\mathrm{C}$ and -70 degrees C. Vet. Med. Int. 2011:341691.
Raizman, E. A., J. P. Fetrow, and S. J. Wells. 2009. Loss of income from cows shedding Mycobacterium avium subspecies paratuberculosis prior to calving compared with cows not shedding the organism on two Minnesota dairy farms. J. Dairy Sci. 92:4929-4936.

Raizman, E. A., S. J. Wells, S. M. Godden, R. F. Bey, M. J. Oakes, D. C. Bentley, and K. E. Olsen. 2004. The distribution of Mycobacterium avium ssp. paratuberculosis in the environment surrounding Minnesota dairy farms. J. Dairy Sci. 87:2959-2966.

Slana, I., P. Kralik, A. Kralova, and I. Pavlik. 2008. On-farm spread of Mycobacterium avium ssp. paratuberculosis in raw milk studied by IS900 and F57 competitive real time quantitative PCR and culture examination. Int. J. Food Microbiol. 128:250-257.

Stabel, J. R. 2008. Pasteurization of colostrum reduces the incidence of paratuberculosis in neonatal dairy calves. J. Dairy Sci. 91:36003606.

Vary, P. H., P. R. Andersen, E. Green, J. Hermon-Taylor, and J. J. McFadden. 1990. Use of highly specific DNA probes and the polymerase chain reaction to detect Mycobacterium paratuberculosis in Johne's disease. J. Clin. Microbiol. 28:933-937.

Vigre, H., I. R. Dohoo, H. Stryhn, and M. E. Busch. 2004. Intra-unit correlations in seroconversion to Actinobacillus pleuropneumoniae and Mycoplasma hyopneumoniae at different levels in Danish multi-site pig production facilities. Prev. Vet. Med. 63:9-28.

Wells, S. J., and B. A. Wagner. 2000. Herd-level risk factors for infection with Mycobacterium paratuberculosis in US dairies and association between familiarity of the herd manager with the disease or prior diagnosis of the disease in that herd and use of preventive measures. J. Am. Vet. Med. Assoc. 216:1450-1457.

Whitlock, R. H. 2010. Paratuberculosis control measures in the USA Pages 319-329 in Paratuberculosis - Organism, Disease and Control. M. A. Behr and D. M. Collins, ed. CABI, Wallingford, UK.

Whitlock, R. H., S. J. Wells, R. W. Sweeney, and J. Van Tiem. 2000. ELISA and fecal culture for paratuberculosis (Johne's disease): Sensitivity and specificity of each method. Vet. Microbiol. $77: 387-398$.

Whittington, R. J., and P. A. Windsor. 2009. In utero infection of cattle with Mycobacterium avium ssp. paratuberculosis: A critical review and meta-analysis. Vet. J. 179:60-69.

Wolf, R., H. W. Barkema, J. De Buck, M. Slomp, J. Flaig, D. Haupstein, C. Pickel, and K. Orsel. 2014a. High herd-level prevalence of $M y-$ cobacterium avium subspecies paratuberculosis in Western Canadian dairy farms, based on environmental sampling. J. Dairy Sci 97:6250-6259. http://dx.doi.org/10.03168/jds.02014-08101.

Wolf, R., F. Clement, H. W. Barkema, and K. Orsel. 2014b. Economic evaluation of participation in a voluntary Johne's disease prevention and control program from a farmer's perspective- The Alberta Johne's Disease Initiative. J. Dairy Sci. 97:2822-2834. 


\section{APPENDIX}

Figure A1. Environmental sample description sheet used to record locations of collected samples.

\section{Environmental sample description sheet \\ (Send with samples)}

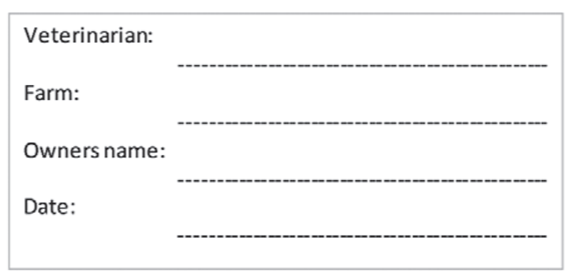

describe sampling location (more than one checkmark per section is possible)

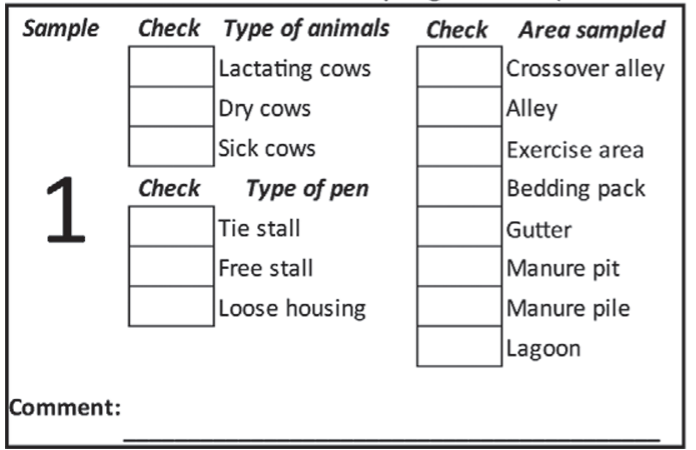

\begin{tabular}{|c|c|c|c|c|}
\hline \multirow[t]{9}{*}{ Sample } & Check & \multirow{5}{*}{$\begin{array}{l}\text { Type of animals } \\
\text { Lactating cows } \\
\text { Dry cows } \\
\text { Sick cows }\end{array}$} & Check & \multirow{2}{*}{$\begin{array}{l}\text { Area sampled } \\
\text { Crossover alley }\end{array}$} \\
\hline & & & & \\
\hline & & & & \multirow{7}{*}{$\begin{array}{l}\text { Alley } \\
\text { Exercise area } \\
\text { Bedding pack } \\
\text { Gutter } \\
\text { Manure pit } \\
\text { Manure pile } \\
\text { Lagoon }\end{array}$} \\
\hline & & & & \\
\hline & Check & & & \\
\hline & & \multirow{4}{*}{$\mid \begin{array}{l}\text { Tie stall } \\
\text { Free stall } \\
\text { Loose housing }\end{array}$} & & \\
\hline & & & & \\
\hline & & & & \\
\hline & & & & \\
\hline \multicolumn{5}{|c|}{ Comment: } \\
\hline
\end{tabular}

Figure A1. 